\title{
Understanding procrastination: A case of a study skills course
}

\author{
T. Hailikari $^{1}$ (D) N. Katajavuori ${ }^{1}$ (D) H. Asikainen ${ }^{1}$ (D)
}

Received: 20 November 2020 / Accepted: 22 February 2021 / Published online: 22 March 2021

(c) The Author(s) 2021

\begin{abstract}
Procrastination is consistently viewed as problematic to academic success and students' general well-being. There are prevailing questions regarding the underlying and maintaining mechanisms of procrastination which are yet to be learnt. The aim of the present study was to combine different ways to explain procrastination and explore how students' time and effort management skills, psychological flexibility and academic self-efficacy are connected to procrastination as they have been commonly addressed separately in previous studies. The data were collected from 135 students who participated in a voluntary time management and well-being course in autumn 2019. The results showed that students' ability to organize their time and effort has the strongest association with procrastination out of the variables included in the study. Psychological flexibility also has a strong individual role in explaining procrastination along with time and effort management skills. Surprisingly, academic self-efficacy did not have a direct association with procrastination. Interestingly, our findings further suggest that time and effort management and psychological flexibility are closely related and appear to go hand in hand and, thus, both need to be considered when the aim is to reduce procrastination. The implications of the findings are further discussed.
\end{abstract}

Keywords Procrastination · Time-management · Psychological flexibility · Academic self-efficacy

T. Hailikari

telle.hailikari@helsinki.fi

N. Katajavuori

Nina.katajavuori@helsinki.fi

H. Asikainen

AsikainenHenna.asikainen@ helsinki.fi

1 Faculty of Educational Sciences, Centre for University Teaching and Learning (HYPE),

University of Helsinki, Helsinki, Finland 


\section{Introduction}

Academic procrastination is very common among university students: almost all occasionally procrastinate in one or another domain of their studies, and approximately every second student regularly procrastinates (Rothblum et al., 1986; Steel, 2007). Considerable attention has been given to procrastination in university setting (Klassen et al., 2008). The student population is especially prone to procrastination, with an estimated prevalence of 50-95\% (Steel, 2007). Procrastination may be defined as 'the voluntary delay of an intended and necessary and/or [personally] important activity, despite expecting potential negative consequences that outweigh the positive consequences of the delay' (Klingsieck, 2013, 26). Typical for procrastination is that it is irrational and not imposed by external matters and it is often accompanied by subjective discomfort and negative consequences (Klingsieck, 2013). Procrastination is often associated with several negative factors, such as lower academic performance (Steel et al., 2001), increased stress (Sirois et al., 2003) and poorer mental health (Stead et al., 2010). Therefore, it is necessary to understand the causes and the factors that maintain procrastination in order to be able to reduce it. The challenge is that research in the area of procrastination often lacks a coherent, theoretical explanation of the behaviour (Glick et al., 2014) which has made it difficult to understand the phenomenon and to follow the research (e.g., Klingsieck, 2013; Schraw et al., 2007; Steel, 2007). Therefore, there are prevailing questions regarding the underlying and maintaining mechanisms of procrastination which are yet to be learnt (Katz et al., 2014; Visser et al., 2018).

The core characteristic of procrastination is the intention-action gap suggesting that the procrastinators often have good intentions, but the challenge lies in the implementation of these intentions (Dewitte and Lens, 2000). Thus, procrastination has traditionally been understood as a self-regulation or time management problem (Wolters et al., 2017). There is a strong body of evidence suggesting that lower levels of self-regulating behaviours are related to higher levels of procrastination, and thus self-regulation is one of the keys to understanding procrastination (Ferrari, 2001). However, Visser et al. (2018) suggest that procrastination is complex behaviour that involves both cognitive and emotional elements as well as evaluations of one's own competence. Recent research suggests that instead of being purely a self-regulation or time management problem, procrastination is also strongly influenced by psychological factors, such as the low confidence in one's own abilities to perform (Steel, 2007) and inability to cope with negative emotions that arise in challenging situations referring to the centrality of psychological flexibility in understanding procrastination (Dionne, 2016; Gagnon et al., 2016). In this article, we aim to bring together these central constructs that have usually been addressed separately in previous studies in order to understand the phenomenon of procrastination and its underlying mechanisms better.

\subsection{Factors explaining academic procrastination}

There are several theoretical perspectives that have been used when exploring procrastination: the differential psychology perspective; the motivational and volitional psychology perspective; the clinical psychology perspective; and the situational 
perspective (Klingsieck, 2013). In the context of higher education, the motivationalvolitional psychology and situational perspectives may be regarded as the most relevant because they provide tangible tools and theories for educational developers to try to influence students' procrastination tendencies whereas the other perspectives focus more on aspects that are not so easily influenced, such as personality traits, depression or personality disorders. The motivational-volitional perspective is focused on the relationship between different motivational and volitional variables such as motivation, self-regulation, time management and learning strategies which are central in successful studying in higher education (Lindblom-Ylänne et al., 2015; Klingsieck, 2013). The situational perspective, on the other hand, focuses on procrastination evoked by situational features, such as the perceived difficulty of the task (Klingsieck, 2013). This situational perspective can be further extended to include the person's reactions to the challenges posed by the situation.

From the motivational-volitional perspective, academic procrastination has been found to be related to lower levels of self-regulation and academic self-efficacy and is associated with higher levels of stress and anxiety (e.g., Ferrari et al., 2005; Howell et al., 2006; Schraw et al., 2007; Wolters, 2003). Klassen et al. (2008) state that among all the variables that have been investigated in relation to academic procrastination, self-regulation, self-efficacy, and self-esteem have received the most attention (see e.g., Cassady and Johnson, 2002; Chun Chu and Choi, 2005; Ferrari, 2001; Howell et al., 2006; Steel, 2007; Wolters, 2003). Procrastination has traditionally been considered to be a form of self-regulation failure, as a weakness of will and low ability to organise own studying (e.g., Ferrari, 2001; Senecal et al., 1995; Steel, 2007) and, thus, one common theory is that procrastination results from a person's inability to manage time (Burka and Yuen, 1982; Glick and Orsillo, 2015).

\subsection{Time and effort management skills behind procrastination}

Research focusing on exploring university students' study progress has consistently shown that time and effort management skills are among the most crucial factors (e.g., Ariely and Wertenbroch, 2002; Entwistle, 2009; Haarala-Muhonen et al., 2011; Häfner et al., 2015; Pintrich, 2004). In the higher education context, time and effort management skills refer to students' ability to set goals for themselves and to study according to their goals, to manage their time usage and to prioritise the tasks to be conducted (Entwistle et al., 2001). It has further been suggested that time and effort management skills provide a foundation for cognitive engagement and student achievement as they refer to how much the students are willing to invest in their learning (Appleton et al., 2008; Fredricks et al., 2004). Previous studies indicate that many higher education students struggle with time and effort management skills (Parpala et al., 2010) and that these skills remain constant throughout the studies and are hard to change (Parpala et al., 2017a). Many students study without study schedules and thus fail to pass the courses because they run out of preparation time, such as for exams (Asikainen et al., 2013). Thus, many interventions to reduce procrastination have focused on improving time management skills (e.g., Ariely and Wertenbroch, 2002; Häfner et al., 2015; Levrini and Prevatt, 2012). 
There are also critical voices claiming that time and effort management skills, or lack thereof, are not enough to explain the phenomena and that research focusing on the role of time and effort management skills in procrastination does not take the persons' internal experiences enough into account (Glick and Orsillo, 2015). It has been suggested that when exploring factors that maintain and cause procrastination, we have to widen the perspective to include a broader theory of regulation of inner experiences, namely, psychological flexibility (Hayes, 2004; Hayes et al., 2012). Recent studies concerning procrastination have brought up the importance of psychological flexibility in decreasing procrastination and suggest that procrastination may also result from person's psychological inflexibility (Eisenbeck et al., 2019; Gagnon et al., 2016; Glick et al., 2014; Scent and Boes, 2014).

\subsection{Psychological flexibility and academic self-efficacy beliefs}

Psychological flexibility refers to one's ability to be consciously present, confronting and accepting the negative experiences, emotions and thoughts one might have, and being able to take action about achieving one's own goals despite unpleasant feelings and thoughts, and further, being able to react to negative feelings and thoughts from a new perspective (Chawla and Ostafin, 2007; Hayes et al., 2006). Thus, it is a central factor influencing the way students react in a stressful and challenging situation. Procrastinators often fail to regulate their actions in situations that are challenging and involve high levels of stress and cognitive workload and avoiding the unpleasant feelings generated by the situation (Ferrari, 2001). This experiential avoidance, or an unwillingness to encounter unpleasant experiences, such as anxiety, is a key component of psychological inflexibility (Sutcliff et al., 2019). Tasks that are considered to be difficult and challenging and do not provide instant rewards tend to be delayed and avoided (Blunt and Pychyl, 2000; Sirois and Pychyl, 2013; Steel, 2007). Escaping from stressful and aversive situations might relieve stress and are thus rewarding. As an example, students are always faced with a trade-off when choosing between procrastinating or studying (Kirby et al., 2005; Olsen et al., 2018). One alternative is to complete the challenging academic tasks on time which leads to delayed rewards in the form of achieving academic and career goals (see e.g., Sutcliff et al., 2019). These goals often strongly align with students' values. However, students always have an alternative to choose an immediate, positive reinforcers in the form of avoidance or escape from negative internal experiences elicited by challenging tasks, such as engaging in social or leisure activities that are not related to the task at hand. Consequently, a number of recent studies have suggested that procrastination is strongly characterised by avoidant tendencies and aversive experiences and is thus mainly involved with the person's ability to deal with negative emotions, in addition to their time and effort management skills (Sirois, 2014; Ticeand Bratslavsky, 2000; Authors, submitted).

Psychological flexibility is thought to be constructed of six core psychological processes, which are cognitive defusion, self-as-context, being present, acceptance, values and committed actions (Hayes et al., 2012). These processes include the ability to observe and recognise ones' own thoughts and seeing them just as thoughts 
rather than truths; keeping a flexible perspective-taking attitude on one's thinking and feeling; the ability to remain in the present moment and be mindful of thoughts, feelings, and sensations without judging them; confronting negative thoughts and emotions without attempting to change them; clarifying one's hopes, values and goals in life and finally, doing and taking actions which are consistent with one's hopes, values and goals (Flaxman et al., 2013; Hayes et al., 2012). Each of these processes is a psychological skill that can be enhanced in different life domains.

Previous research has clearly shown a link between high levels of procrastination and psychological inflexibility. Eisenbeck et al. (2019) found that procrastination and psychological distress were associated with psychological inflexibility and further, psychological inflexibility mediated the relationship between general psychological distress and procrastination. The role of psychological flexibility's sub-processes in procrastination among university students has also been studied, and it was found that committed actions were moderately negatively correlated with procrastination suggesting that committed action could be a promising variable in the study of procrastination (Gagnon et al. 2016). Another study showed that procrastination was negatively and moderately related to lower levels of acceptance, adding support to the negative link between psychological flexibility and procrastination (Glick et al., 2014). The significance of psychological flexibility in the university context has been studied less, but recent research in this context showed that psychological flexibility has a strong relationship with student engagement and study progression (Asikainen, 2018; Asikainen et al., 2018).

A recent study by Jeffords et al. (2018), showed that psychological flexibility is closely related to self-efficacy. Self-efficacy has often been studied previously, focusing on procrastination with results showing an inverse relationship with procrastination (Howell and Watson, 2007; Steel, 2007; Wolters, 2003). Academic Self-efficacy beliefs describe students' beliefs in their own capabilities to learn new things and to complete given tasks successfully (Bandura, 1997). According to the study by Jeffords et al. (2018) students who reported greater psychological flexibility felt more efficacious in their ability to complete their studies, whereas students who reported greater inflexibility also reported feeling less efficacious. Similar findings have been reported in relation to students' time and effort management skills. Bembenutty (2009) showed that college students who have greater academic self-efficacy also tend to show increased management of their time and study environment (see also Burlison et al., 2009; Park and Sperling, 2012). Academic Self-efficacy beliefs have been proposed as a possible explanation for procrastination in the academic context, indicating that low academic self-efficacy beliefs are associated with an increased tendency to procrastinate (Judge and Bono, 2001). If one's academic self-efficacy beliefs are low, the motivation to initiate work or to commit to required action should also be low, resulting in avoidance behaviour and consequently procrastination (Grunschel et al. 2013). On the other hand, students who believe that they can and will do well are more likely to be motivated to self-regulate, persist and engage in studying (Pintrich and Schunk, 2002; Zimmerman, 2000). Academic Self-efficacy beliefs have been found to be among the strongest predictive factors of performance in various domains (e.g., Lane and Lane, 2001; Pajares, 1996). Thus, when exploring the maintaining factors of procrastination, it is important to include academic self-efficacy. 


\subsection{Aim of the study}

Taken together, previous research suggests that time and effort management skills, psychological flexibility and self-efficacy are all closely related to procrastination. Although the studies in this area support a tentative connection between these factors, it is far from conclusive. To our knowledge, no previous study has brought together these central constructs in explaining procrastination. They have been explored separately as they represent different research traditions. The aim of the present study is to include all these variables and explore their interrelations and how they together predict procrastination among students that experiences challenges with their study skills. There is a need to understand the underlying mechanisms of procrastination and which constructs are especially important if the aim is to reduce procrastination among higher education students. This research focuses on answering the following research question: How are university students' time and effort management skills, psychological flexibility and self-efficacy associated with (a) each other and (b) to their reported level of procrastination.

\section{Methodology}

\subsection{Participants}

The data were collected from students studying arts and humanities at a Finnish university. Prolonged study times are a great challenge at the Faculty of Arts and Humanities (Kurri, 2006). Recent research also suggests that students procrastinate more in the field of arts and humanities compared to other academic fields (Nordby et al., 2017). The data came from the students who participated in a voluntary time management and well-being course, and who were willing/eager to improve their study skills. This course was advertised for students who have challenges with their time-management and well-being. A total of 149 students voluntarily participated in the study and answered the questionnaire in autumn 2019. Students responded to the questionnaires at the beginning of the course as a part of their pre-assignment. Of these students, 14 were excluded because their answers had many missing values concerning the measured dimensions $(>50 \%)$. Thus, a total of 135 students provided the data. In the questionnaire, the students were asked to evaluate their own time and effort management skills, academic self-efficacy, tendency to procrastinate and psychological flexibility. Of these students, 22 were male students and 110 female students. Two students identified as 'other gender', and one did not answer this question. Approximately a quarter of the students in the Faculty of Arts are male and, thus, the sample distribution is similar to the population. The average age of the participants was 28.1 years $(\mathrm{SD}=7.62)$.

\subsection{Instruments}

We used two scales, focusing on time and effort management skills and academic selfefficacy, from the HowULearn questionnaire (Parpala and Lindblom-Ylänen, 2012). 
HowULearn -questionnaire and its scales are widely used and validated in Finnish and international contexts (e.g., Cheung et al., 2020; Parpala et al., 2010; Postareff et al., 2018; Ruohoniemi et al., 2017; Rytkönen et al., 2012). The HowULearn questionnaire has also been translated in the context of Danish higher education (Herrmann et al., 2017). Time and effort management skills are measured with four items on a Likert-scale from 1 to 5 (e.g. 'I am generally systematic and organised in my studies'). Concerning students' academic self-efficacy, we used a scale from HowULearn questionnaire which has been constructed based on (Pintrich and Garcia (1991) Motivated Strategies for Learning Questionnaire (MSLQ). Five items, using a Likert scale from 1 to 5, were modified to suit the academic self-efficacy. As it is applied here, academic self-efficacy refers to students' appraisal of their ability to master academic tasks including their judgements about their ability to accomplish a task as well as their confidence in their skill to perform that task. Based on these items, an academic self-efficacy scale for constructed (5 items, e.g., 'I believe I will do well in my studies as long as I make an effort'). Psychological flexibility was measured according to the work-related acceptance and action questionnaire (WAAQ) (Bond et al., 2013) which was recently developed to fit the higher education context in Finland (7 items, e.g., 'My worries do not prevent me from succeeding in my studies' (Asikainen, 2018). The items used a 7 -point Likert scale $(1=$ totally disagree, $7=$ totally agree). Procrastination was measured with a short version of the Pure procrastination scale (PPS) (Svartdahl and Steel, 2017) using a 5-point Likert scale (5 items, e.g., In preparation for some deadlines, I often waste time by doing other things'). This short version of the original pure procrastination scale has been proven to be a robust instrument to measure academic procrastination (Svartdahl et al., 2017; see also Klein et al., 2019).

\subsection{Statistical analysis}

Missing value analysis was conducted on the items measuring the scales. There were only four separate missing values concerning different items and, thus, these were replaced with means. The relationships between the scales were analysed with Pearson's correlation analysis. In addition, linear regression analysis was conducted on the scales measuring academic self-efficacy, time and effort management (=organised studying) and psychological flexibility explaining procrastination. In addition, the students were then divided into three score groups (low/medium/high) based on their scores measuring time and effort management and psychological flexibility where the middle group was formed using the mean +- a half standard deviation. The groups were combined and thus, six score groups were conducted. The differences in these groups in procrastination was analysed with One-way ANOVA and Tukey's test.

\section{Results}

According to the Cronbach alpha analysis, the scales measuring psychological flexibility, procrastination and academic self-efficacy had very good reliability $(\alpha=0.83-0.90)$. The reliability for the scale measuring time and effort management 
can be regarded as acceptable (see Table 1). Adding more items to measure the same dimension, would most probably have increased the alpha on Organised studying (Taber 2018). However, as the scale has been used in many previous studies with good reliability (Herrmann et al., 2017; Parpala et al., 2010; Ruohoniemi et al., 2017) its use can be considered to be acceptable.

The correlational analysis showed that there was a clear relationship between procrastination, psychological flexibility, academic self-efficacy and time and effort management skills. Procrastination was statistically significantly and negatively correlated with time and effort management skills $(\mathrm{r}=-0.584, p<0.001)$, academic self-efficacy $(p=-0.358, p<0.001)$ and psychological flexibility $(r=-0.461$, $p<0.001)$. In addition, academic self-efficacy was positively related to psychological flexibility $(p=0.322, p<0,001)$ and time and effort management skills $(p=0.357, p<0.001)$. In addition, time and effort management skills and psychological flexibility correlated positively with each other $(r=0.332, p<0.001)$. The correlations can be seen in Table 2.

\subsection{Regression analysis}

A linear regression model was conducted with psychological flexibility, time and effort management and academic self-efficacy as predictors of procrastination. As presented in Table 3, time and effort management skills, psychological flexibility and academic self-efficacy explained a significant level of variance in procrastination (Adjusted $\mathrm{R}$ Square $=0.382)$. Both time and effort management $(\mathrm{t}=-5.63$, $p<0.001)$ and psychological flexibility $(\mathrm{t}=-3.06, p=0.003)$ explained the variance in procrastination statistically significantly meaning that students who reported greater use of time and effort management strategies and higher psychological flexibility reported less tendency to procrastinate. Academic self-efficacy failed to emerge as an individual predictor of procrastination $\mathrm{t}=-1.04, p=0.301$ ). The results of the regression analysis can be seen in Table 3.

\subsection{Differences in score groups}

The One-way ANOVA of the score groups showed that there were differences in experiences of procrastination according to the score groups. According to the Tukey's test, the group with a high score on time and effort management as well as psychological flexibility scored statistically significantly lower on procrastination than the other score groups (see Table 4). In addition, the group with a low score in time and effort management as well as on psychological flexibility scored higher in procrastination than the group scoring average on time and effort management and high on psychological flexibility as well as the group scoring high on time and effort management and average on psychological flexibility. The group scoring average on time and effort management and low on psychological flexibility also scored statistically significantly higher on procrastination than the group scoring high on time and effort management and average on psychological flexibility. 
Table 1 Frequencies and example items of the scales

\begin{tabular}{|c|c|c|c|c|}
\hline Scale & Mean & SD & $\alpha$ & Example item \\
\hline Procrastination & 3.97 & 0.86 & 0.86 & $\begin{array}{l}\text { In preparing for some deadlines, I often } \\
\text { waste time by doing other things }\end{array}$ \\
\hline Psychological flexibility & 3.47 & 1.26 & 0.90 & $\begin{array}{l}\text { My worries do not prevent me from suc- } \\
\text { ceeding in my studies }\end{array}$ \\
\hline Self-efficacy & 3.59 & 0.77 & 0.83 & I expect to do very well in my studies \\
\hline $\begin{array}{l}\text { Time and effort man- } \\
\text { agement }\end{array}$ & 2.62 & 0.76 & 0.65 & $\begin{array}{l}\text { I organise my study time carefully to make } \\
\text { the best use of it }\end{array}$ \\
\hline
\end{tabular}

\section{Discussion}

Procrastination is consistently viewed as problematic to academic success and students' general well-being (Steel, 2007). Students' time management skills as well as ability to manage their own actions despite the negative feelings have been identified as central factors associated with procrastination along with students' academic self-efficacy beliefs. To this point, however, only a few studies have included all these measures and compared their impact on procrastination. Thus, an aim with the present study was to explore how students' time and effort management skills, psychological flexibility and academic self-efficacy are interrelated and associated with procrastination as they have been commonly addressed separately in previous studies.

Designed to address this limitation, our findings support three noteworthy findings regarding academic procrastination among students who experience problems in their time management skills. Firstly, our findings show that students' ability to organise their time and effort had the strongest association with procrastination out of the variables included in the study. Secondly, our findings indicate that psychological flexibility has a strong individual role in explaining procrastination along with time and effort management skills, although to a slightly smaller degree. And thirdly, our findings suggest that these two constructs appear to be closely related and clearly go hand in hand and, thus, both need to be considered. In the remainder of this section, we review the findings that support these points, identify implications for research and practice, and discuss some limitations to these conclusions.

Time management has been repeatedly identified in previous studies as a major factor contributing to procrastination (Ferrari, 2001; Senécal et al., 1995; Steel, 2007; Wolters, 2003). Our findings add to this work by showing that in our study time and effort management skills were strongly related to self-reported level of procrastination and explained the largest variance of procrastination in the regression. This finding implies that students' time and effort management skills can be used to understand their self-reported levels of academic procrastination. However, it appears that time and effort management skills alone are not enough to explain the phenomenon of procrastination as we assumed. In our study, psychological flexibility also had a strong individual role in explaining large variation of procrastination. 
Table 2 Correlations between the scales

\begin{tabular}{lllll}
\hline & TE & PF & SE & PR \\
\hline TEM time and effort management & 1 & & & \\
PF psychological flexibility & $.332^{* *}$ & 1 & 1 & \\
SE self-efficacy & $.357^{* *}$ & $.433^{* *}$ & 1 \\
PR procrastination & $-.584^{* *}$ & $-.461^{*}$ & $-.358^{* *}$ & 1 \\
\hline
\end{tabular}

$* * p<0.001$

Table 3 Regression analysis: factors explaining procrastination

\begin{tabular}{llll}
\hline Scales & Beta & $\mathrm{t}$ & $p$ \\
\hline Time and effort management & -.447 & -5.627 & $<.001$ \\
Psychological flexibility & -.253 & -3.059 & .003 \\
Self-efficacy & -.086 & -1.040 & .301 \\
\hline
\end{tabular}

*Adjusted R square $=0.382$

Table 4 Differences in procrastination means between different score groups

\begin{tabular}{lrll}
\hline Group & $\mathrm{N}$ & $\begin{array}{l}\text { Procrastination } \\
\text { mean }\end{array}$ & Tuckey's test $p$ values \\
\hline 1 LowTEM_LowFlexibility & 19 & 4,63 & $>6^{* *, 8,9 * * *}$ \\
2 LowTEM_AverageFlexibility & 14 & 4,31 & $>9^{* * *}$ \\
3 LowTEM_HighFlexibility & 6 & 4,40 & $>9 * * *$ \\
4 AverageTEM_LowFlexibility & 18 & 4,38 & $>8^{*}, 9^{* * *}$ \\
5 AverageTEM_AverageFlexibility & 21 & 4,12 & $>9^{* * *}$ \\
6 AverageTEM_HighFlexibility & 18 & 3,80 & $<1^{* *},>9 * *$ \\
7 HighTEM_LowFlexibility & 7 & 3,74 & $>9^{*}$ \\
8 HighTEMAverageFlexibility & 15 & 3,57 & $<1^{* * *}, 4^{*},>9 *$ \\
9 HighTEMd_HighFlexibity & 17 & 2,78 & $<1,2,3,4,5^{* * *}, 6^{* *}, 7,8^{*}$ \\
\hline
\end{tabular}

$T E M=$ time and effort management, flexibility = psychological flexibility

$* * * p<0.001, * * p<0.01, * p<0.05$

This is in line with the recent research suggesting that psychological flexibility is also a central construct explaining procrastination (Dionne, 2016; Gagnon et al. 2016). These two factors were also strongly correlated with each other as well as with academic self-efficacy beliefs which suggests that they share common variance. Their central role was further explained by regression analysis which showed that together they explained almost $40 \%$ of the variance in procrastination. Interestingly, in the present study academic self-efficacy beliefs did not have a direct association with procrastination. This finding is in contrast with previous studies showing that lower self-efficacy beliefs are associated with an increased tendency to procrastinate (Judge and Bono, 2001; Wolters, 2003). However, some studies have similarly 
reported a non-significant association between self-efficacy and procrastination. For example, Klassen et al. (2010) showed with Canadian and Singaporean students that although procrastination negatively and significantly correlated with academic selfefficacy, in the regression model there was no association between academic selfefficacy and procrastination. Only self-efficacy for self-regulation and self-esteem had a significant relationship with procrastination (Klassen et al., 2010). This finding is very similar to our result. The most likely explanation for the result is that time and effort management skills and psychological flexibility have a more direct and stronger relationship with procrastination than academic self-efficacy even though it is closely related to all these constructs. It might be that if one is committed to value-based actions which are at the core of psychological flexibility, the negative thoughts one might have about oneself may not be hindering one's goal-based actions (Hayes et al., 2006). This is an interesting finding, and it would be useful to study it in more detail in subsequent studies.

As a third noteworthy finding, our findings provide insight into the relations between time and effort management and psychological flexibility as factors contributing to procrastination. Psychological flexibility and time and effort management skills appear to go hand in hand. When the students were divided to three groups based on their scores on psychological flexibility and time and effort management, the largest groups were the ones in which both time and effort managements skills and psychological flexibility were either low or high. The groups where one of these measures would be high and the other would be low were the smallest in implicating their close relationship. Therefore, it seems that if a person rates his/her time and effort management skills highly, he/she rates his/her psychological flexibility high as well. Also, significant correlations between these measures support this notion. A significant positive correlation between time and effort management and psychological flexibility has also been found in previous study (Asikainen et al., 2019). Interestingly, the group that rated both time and effort management and psychological flexibility highly rated their tendency to procrastinate as markedly low compared to other groups. The opposite phenomenon was true for the group that rated their time and effort management skills and psychological flexibility low. This group rated their tendency to procrastinate very highly. Interestingly, if the rating on one of these measures, especially on time and effort management studying was lower, the tendency to procrastinate increased drastically. Although this conclusion fits with common-sense expectations regarding these constructs and their relationship, our findings are the first to establish this relationship empirically.

One implication of this finding is that future efforts to remediate students' procrastination should account for both these factors. Only when accounting for both time and effort management and psychological flexibility can students' procrastination be understood. Instead of taking procrastination merely as a self-regulation problem, it is also strongly influenced by a person's inability to cope with negative emotions that arise in challenging situations (Eisenbeck et al., 2019; Gagnon et al., 2016; Glick et al., 2014). It may be suggested that time and effort management support psychological flexibility. Some studies on time allocation suggest that psychological flexibility process includes allocating one's time to important and valuebased actions in everyday life (Kashdan and Rottenberg, 2010). Thus, when time 
is allocated to support value-based action well-being also increases (Sheldon et al., 2010). Thinking about your own values and setting goals can also be considered to be a central part of both time and effort management (Entwistle and McCune, 2004) and psychological flexibility (Hayes et al., 2006). Thus, we could suggest that when practising psychological flexibility, time management is a part of the process in which one needs to plan how to allocate time to support one's own personal values. Fostering students' psychological flexibility as well as time and effort managements skills, could be a promising tool to decrease procrastination. As procrastinators often fail to regulate their actions in challenging or stressful situations (Ferrari, 2001), it might be that psychological flexibility could be a central construct. More attention should be paid to encouraging students to pursue value-based committed actions, despite the negative thoughts and feelings one might have. Thus, students' capacity to cope with their negative thoughts and emotions should be enhanced during their studying (Asikainen, 2018).

\subsection{Limitations}

There are also some limitations that should be addressed. The participants consisted of a selected sample of students which most probably influenced the results. The students took part in a time management and well-being course which was directed especially at those students who had experienced problems with their studies. Thus, the sample of the students in this study was selected and most probably consisted mostly of students who were eager and motivated to improve their time management skills and studying. That might also explain why the time and effort management skills were the strongest explanatory variable of procrastination in the present study. Thus, these results of the study are not generalisable to general student population and the selected sample most probably influenced the results. More research is still needed with a bigger and more representative population. Studies should also explore the role of time and effort management skills in procrastination with a more representative student population. The number of participants was rather low which gave limited opportunities for analysis. For example, the number of students in different score groups was rather low, and in some cases too low for the analysis. Therefore, the results should be interpreted with care. Still, we wanted to include the One Way Anova analysis in our study as it clearly showed that psychological flexibility and time and effort management skills are aligned with each other and students with high scores in both of these dimensions report much less procrastination than other students. Furthermore, one major limitation of the study is that the data are based solely on self-reports. This means that we have measured students' experiences of these variables. However, we used validated questionnaires which have been shown to be reliable in measuring these constructs and thus, we argue that these results also bring valuable insights to research in procrastination which should be further explored. Future research should also include other measures such as accumulation of credits to see how these measures relate to students' study progression. In addition, our data are also cross-sectional in nature and thus represents only one particular timeframe. Thus, it is not possible to draw any conclusions regarding 
the predictive value of the variables. In future research we should also include longitudinal data to explore more closely the relationship between these measures. Despite of the numerous limitations in our study, we argue that this paper provides a novel exploration of these predictors of procrastination together which has not been provided in previous studies.

\subsection{Practical implications and conclusions}

One promising way to support students' psychological flexibility and learning processes could be to combine study skills courses, such as time and effort management intervention courses with acceptance and commitment therapy (ACT)based intervention courses, in which students could practise tolerating stress and negative thoughts as well as developing their time and effort management. Recent studies (Asikainen et al., 2019) have shown that this kind of ACT-interventions including reflection of one's own study processes and practising new ways to study, in this way practising new ways to study, can enhance students' psychological flexibility and time and effort management and in this way, foster students' well-being and study skills. ACT-based intervention has shown to have multiple positive effects on students' well-being and studying (Asikainen et al., 2019; Levin et al. 2017; Räsänen et al. 2016). In addition, ACT-based training can help students to manage psychological inflexibility and encourage persistence behaviour, which in turn is likely to have a positive impact on students' self-efficacy and further, to their academic performance (Jeffords et al. 2018). Earlier studies have found that ACT-based interventions targeted at students who suffer from procrastination can decrease experiences of procrastination (Scent and Boes, 2014; Wang et al., 2015). One study has suggested that different core processes of psychological flexibility have different effects on procrastination. That is, although all the components correlate with procrastination, acceptance and committed actions significantly predict experiences of procrastination (Gagnon et al., 2016). Thus, it seems that being more open and accepting of one's emotional experiences or thoughts and being willing to engage in difficult activities to persist in the direction of important values is important in reducing procrastination.

As time and effort management in our study was the predominant factor associated with procrastination, we suggest that time management should be promoted for higher education students. It has been shown that many students have trouble with time management (Parpala et al., 2010). Many studies have shown that different time management strategies are beneficial for different students. These include things like setting goals and planning how to achieve these (Häfner et al., 2015), setting deadlines (Ariely and Wertenbroch, 2002) and monitoring time use (Asikainen et al., 2019). These skills should be enhanced during university study because it has been shown that time and effort management skills remain rather constant without a conscious effort to influence them (Lindblom-Ylänne et al., 2017).

To conclude, our study brings novel insights into the underlying mechanisms of procrastination. Our study showed that both psychological flexibility and time management are important factors influencing procrastination, and furthermore, they 
appear to be closely related factors and together influence procrastination behavior. Thus, both these factors should be considered when the focus is on reducing procrastination. Students who tend to procrastinate might benefit from trainings that focus on training both time management skills and psychological flexibility and not focusing on only either one. This might produce the best results.

Author contributions The idea for the article was by TH. All authors contributed to the study conception and design. Material preparation and data collection were performed by $\mathrm{TH}$ and the analysis were performed by HA. The first draft of the manuscript was written by $\mathrm{TH}$ and NK was responsible for writing the parts regarding psychological flexibility and discussion. All authors commented on previous versions of the manuscript. All authors read and approved the final manuscript.

Funding Open access funding provided by University of Helsinki including Helsinki University Central Hospital. No funding provided for the study.

Data availability The data is available on demand.

\section{Declarations}

Conflicts of interest The authors declare that they have no conflict of interest.

Ethics approval This study was conducted followed by the ethical principles of research with human participants and ethical review in the human sciences in Finland. https://tenk.fi/en/ethical-review/ethic al-review-human-sciences

Consent to participate The participants were fully informed about the purpose of the study and the use of materials. Written consent was obtained from all the participants.

Consent for publication The participants were fully informed that the obtained materials will be used for research and publication purposes.

Open Access This article is licensed under a Creative Commons Attribution 4.0 International License, which permits use, sharing, adaptation, distribution and reproduction in any medium or format, as long as you give appropriate credit to the original author(s) and the source, provide a link to the Creative Commons licence, and indicate if changes were made. The images or other third party material in this article are included in the article's Creative Commons licence, unless indicated otherwise in a credit line to the material. If material is not included in the article's Creative Commons licence and your intended use is not permitted by statutory regulation or exceeds the permitted use, you will need to obtain permission directly from the copyright holder. To view a copy of this licence, visit http://creativecommons.org/licen ses/by/4.0/.

\section{References}

Ariely, D., \& Wertenbroch, K. (2002). Procrastination, deadlines, and performance: Self-control by precommitment. Psychological Science, 13(3), 219-224.

Asikainen, H. (2018). Examining indicators for effective studying - The interplay between student integration, psychological flexibility and self-regulation in learning. Psychology, Society, \& Education, 10(2), 225-237.

Asikainen, H., Hailikari, T., \& Mattsson, M. (2018). The interplay between academic emotions, psychological flexibility and self-regulation as predictors of academic achievement. Journal of Further and Higher Education, 42(4), 439-453. 
Asikainen, H. \& Kaipainen, K. \& Katajavuori, N. (2019). Understanding and promoting students' wellbeing and performance in university studies. Journal of University Teaching \& Learning Practice, 16(5), 1-15.

Asikainen, H., Virtanen, V., Parpala, A., \& Lindblom-Ylänne, S. (2013). Understanding the variation in bioscience students' conceptions of learning in the 21st century. International Journal of Educational Research, 62, 36-42.

Bandura, A. (1997). Self-efficacy: The exercise of control. Freeman.

Bembenutty, H. (2009). Academic delay of gratification, self-regulation of learning, gender differences, and expectancy-value. Personality and Individual Differences, 46(3), 347-352.

Blunt, A. K., \& Pychyl, T. A. (2000). Task aversiveness and procrastination: A multi-dimensional approach to task aversiveness across stages of personal projects. Personality and Individual Differences, 28(1), 153-167.

Burka, J. B., \& Yuen, L. M. (1982). Mind games procrastinators play. Psychology Today, 16(1), $32-34$.

Burlison, J. D., Murphy, C. S., \& Dwyer, W. O. (2009). Evaluation of the motivated strategies for learning questionnaire for predicting academic performance in college students of varying scholastic aptitude. College Student Journal, 43(4), 1313-1324.

Cassady, J. C., \& Johnson, R. E. (2002). Cognitive test anxiety and academic performance. Contemporary Educational Psychology, 27(2), 270-295.

Chawla, N., \& Ostafin, B. (2007). Experiential avoidance as a functional dimensional approach to psychopathology: An empirical review. Journal of Clinical Psychology, 63(9), 871-890.

Chun Chu, A. H., \& Choi, J. N. (2005). Rethinking procrastination: Positive effects of "active" procrastination behavior on attitudes and performance. The Journal of Social Psychology, 145(3), 245-264.

Dewitte, S., \& Lens, W. (2000). Procrastinators lack a broad action perspective. European Journal of Personality, 14(2), 121-140.

Dionne, F. (2016). Using acceptance and mindfulness to reduce procrastination among university students: Results from a pilot study. Revista Prâksis, 1, 8-20.

Eisenbeck, N., Carrenob, D. F., \& Uclés-Juárezb, U. (2019). From psychological distress to academic procrastination: Exploring the role of psychological inflexibility. Journal of Contextual Behavioral Science, 13, 103-108.

Entwistle, N. (2009). Teaching for understanding at university. Palgrave Macmillan.

Entwistle, N., \& McCune, V. (2004). The conceptual bases of study strategy inventories. Educational Psychology Review, 16(4), 325-346.

Entwistle, N., McCune, V., \& Walker, P. (2001). Conceptions, styles, approaches within higher education: analytic abstractions and everyday experience. In R. J. Sternberg \& L.-F. Zhang (Eds.), Perspectives on thinking, learning, and cognitive styles (pp. 73-102). Lawrence Erlbaum Associates Inc.

Ferrari, J. R. (2001). Procrastination as self-regulation failure of performance: effects of cognitive load, self-awareness, and time limits on 'working best under pressure. European journal of Personality, 15(5), 391-406.

Ferrari, J. R., O’Callaghan, J., \& Newbegin, I. (2005). Prevalence of procrastination in the United States, United Kingdom, and Australia: arousal and avoidance delays among adults. North American Journal of Psychology, 7(1), 1-6.

Flaxman, P., Bond, F., Livheim, F., \& Hayes, S. (Eds.). (2013). The mindful and effective employee: An acceptance and commitment therapy training manual for improving well-being and performance. New Harbinger Publishers.

Gagnon, J., Dionne, F., \& Pychyl, T. A. (2016). Committed action: An initial study on its association to procrastination in academic settings. Journal of Contextual Behavioral Science, 5(2), 97-102.

Glick, D. M., Millstein, D. J., \& Orsillo, S. M. (2014). A preliminary investigation of the role of psychological inflexibility in academic procrastination. Journal of Contextual Behavioral Science, 3(2), 81-88. https://doi.org/10.1016/j.jcbs.2014.04.002

Glick, D. M., \& Orsillo, S. M. (2015). An investigation of the efficacy of acceptance-based behavioral therapy for academic procrastination. Journal of Experimental Psychology: General, 144(2), 400-409.

Grunschel, C., Patrzek, J., \& Fries, S. (2013). Exploring the reasons and consequences of academic procrastination: An interview study. European Journal of Psychology of Education, 28(3), 841-861. https://doi.org/10.1007/s10212-012-0143-4

Haarala-Muhonen, A., Ruohoniemi, M., \& Lindblom-Ylänne, S. (2011). Factors affecting the study pace of first-year law students: in search of study counselling tools. Studies in Higher Education, 36(8), 911-922. 
Hailikari, T., Nieminen, J. H., \& Asikainen, H. (submitted). The ability of psychological flexibility to predict study success and its relations to cognitive attributional strategies and academic emotions.

Hayes, S. C. (2004). Acceptance and commitment therapy, relational frame theory, and the third wave of behavioral and cognitive therapies. Behavior Therapy, 35(4), 639-665.

Hayes, S., Luoma, J., Bond, F., Masuda, A., \& Lillis, J. (2006). Acceptance and commitment therapy: Model, processes, and outcomes. Behaviour Research and Therapy, 44(1), 1-25.

Hayes, S. C., Pistorello, J., \& Levin, M. E. (2012). Acceptance and commitment therapy as a unified model of behavior change. The Counseling Psychologist, 40(7), 976-1002.

Herrmann, K. J., Bager-Elsborg, A., \& Parpala, A. (2017). Measuring perceptions of the learning environment and approaches to learning: validation of the learn questionnaire. Scandinavian Journal of Educational Research, 61(5), 526-539.

Howell, A. J., Watson, D. C., Powell, R. A., \& Buro, K. (2006). Academic procrastination: The pattern and correlates of behavioural postponement. Personality and Individual Differences, 40(8), 1519-1530.

Häfner, A., Stock, A., \& Oberst, V. (2015). Decreasing students' stress through time management training: An intervention study. European Journal of Psychology of Education, 30(1), 81-94.

Jeffords, J. R., Bayly, B. L., Bumpus, M. F., \& Hill, L. G. (2018). Investigating the relationship between university students' psychological flexibility and college self-efficacy. Journal of College Student Retention: Research, Theory and Practice, 22(2), 351-372.

Judge, T. A., \& Bono, J. E. (2001). Relationship of core self-evaluations traits—self-esteem, generalized self-efficacy, locus of control, and emotional stability - with job satisfaction and job performance: A meta-analysis. Journal of Applied Psychology, 86, 80-92.

Kashdan, T. B., \& Rottenberg, J. (2010). Psychological flexibility as a fundamental aspect of health. Clinical psychology review, 30(7), 865-878.

Katz, I., Eilot, K., \& Nevo, N. (2014). "I'll do it later": Type of motivation, self-efficacy and homework procrastination. Motivation and Emotion, 38(1), 111-119.

Kirby, K. N., Winston, G. C., \& Santiesteban, M. (2005). Impatience and grades: Delay-discount rates correlate negatively with college GPA. Learning and Individual Differences, 15(3), 213-222.

Klassen, R. M., Ang, R., Chong, W., Krawchuk, L., Huan, V., Wong, I., \& Yeo, L. (2010). Academic Procrastination in two settings: Motivation correlates, behavioral patterns, and negative impact of procrastination in Canada and Singapore. Applied Psychology, 59(3), 361-379.

Klassen, R. M., Krawchuk, L. L., \& Rajani, S. (2008). Academic procrastination of undergraduates: Low self-efficacy to self-regulate predicts higher levels of procrastination. Contemporary Educational Psychology, 33(4), 915-931.

Klein, E. M., Beutel, M. E., Müller, K. W., Wölfling, K., Brähler, E., \& Zenger, M. (2019). Assessing procrastination. European Journal of Psychological Assessment, 35, 633-640.

Klingsieck, K. B. (2013). Procrastination. When good things don't come to those who wait." European Psychologist, 18(1), 24-34.

Kurri, E. (2006). Opintojen pitkittymisen dilemma. Tutkimus opintojen sujumattomuustekijöistä yliopistossa ja niihin vaikuttamisen keinoista [The Dilemma of Prolonged Studies. A Research on Reasons behind Prolonged Studies and How to Make a Change]. Otus (Research Foundation of the Finnish Student Unions) 27. Helsinki: University Press.

Lane, J., \& Lane, A. (2001). Self-efficacy and academic performance. Social Behavior and Personality: An International Journal, 29, 687-693.

Levin, M. E., Haeger, J. A., Pierce, B. G., \& Twohig, M. P. (2017). Web-based acceptance and commitment therapy for mental health problems in college students: A randomized controlled trial. Behavior Modification, 41(1), 141-162.

Levrini, A., \& Prevatt, F. (2012). Succeeding with adult ADHD: Daily strategies to help you achieve your goals and manage your life. American Psychological Association.

Lindblom-Ylänne, S., Haarala-Muhonen, A., Postareff, L., \& Hailikari, T. (2017). Exploration of individual study paths of successful first-year students: an interview study. European Journal of Psychology of Education, 32(4), 687-701.

Lindblom-Ylänne, S. A., Saariaho-Räsänen, E. J., Inkinen, M. S., Haarala-Muhonen, A. E., \& Hailikari, T. K. (2015). Academic procrastinators, strategic delayers and something betwixt and between: An interview study. Frontline Learning Research, 3(2), 47-62. 
Nordby, K., Klingsieck, K. B., \& Svartdal, F. (2017). Do procrastination-friendly environments make students delay unnecessarily? Social Psychology of Education, 20(3), 491-512.

Olsen, R. A., Macaskill, A. C., \& Hunt, M. J. (2018). A measure of delay discounting within the academic domain. Journal of Behavioral Decision Making, 31(4), 522-534.

Pajares, F. (1996). Self-efficacy beliefs in academic settings. Review of Educational Research, 66(4), $543-578$.

Park, S. W., \& Sperling, R. A. (2012). Academic procrastinators and their self-regulation. Psychology, 3(1), $12-23$.

Parpala, A., \& Lindblom-Ylänne, S. (2012). Using a research instrument for developing quality at the university. Quality in Higher Education, 18(3), 313-328.

Parpala, A., Asikainen, H., Ruohoniemi, M., \& Lindblom-Ylänne, S. (2017). The relationship between the development of time and effort management and experiences of the teaching-learning environment in a university context. International Journal of Learning and Change, 9(2), 170-184.

Parpala, A., Lindblom-Ylänne, S., Komulainen, E., Litmanen, T., \& Hirsto, L. (2010). Students' approaches to learning and their experiences of the teaching-learning environment in different disciplines. British Journal of Educational Psychology, 80(2), 269-282.

Pintrich, P. R., \& Garcia, T. (1991). Student goal orientation and self-regulation in the college classroom. In M. L. Maher \& P. R. Pintrich (Eds.), Advances in motivation and achievement (Vol. 7, pp. 371-402). JAI Press.

Pintrich, P. R. (2004). A conceptual framework for assessing motivation and self-regulated learning in college students. Educational Psychology Review, 16(4), 385-407.

Pintrich, P. R., \& Schunk, D. H. (2002). Motivation in education: Theory, research, and applications. Prentice Hall.

Rothblum, E. D., Solomon, L. J., \& Murakami, J. (1986). Affective, cognitive, and behavioral differences between high and low procrastinators. Journal of Counseling Psychology, 33(4), 387-394.

Ruohoniemi, M., Forni, M., Mikkonen, J., \& Parpala, A. (2017). Enhancing quality with a research-based student feedback instrument: A comparison of veterinary students' learning experiences in two culturally different European universities. Quality in Higher education, 23(3), 249-263.

Räsänen, P., Lappalainen, P., Muotka, J., Tolvanen, A., \& Lappalainen, R. (2016). An online guided ACT intervention for enhancing the psychological wellbeing of university students: A randomized controlled clinical trial. Behaviour Research and Therapy, 78, 30-42.

Scent, C. L., \& Boes, S. R. (2014). Acceptance and commitment training: A brief intervention to reduce procrastination among college students. Journal of College Student Psychotherapy, 28(2), 144-156.

Senecal, C., Koestner, R., \& Vallerand, R. J. (1995). Self-regulation and academic procrastination. The Journal of Social Psychology, 135(5), 607-619.

Schraw, G., Wadkins, T., \& Olafson, L. (2007). Doing the things we do: A grounded theory of academic procrastination. Journal of Educational psychology, 99(1), 12-25.

Sheldon, K. M., Cummins, R., \& Khamble, S. (2010). Life-balance and well-being: Testing a two-pronged conceptual and measurement approach. Journal of Personality, 78, 1093-1134.

Sirois, F. M. (2014). Procrastination and stress: Exploring the role of self-compassion. Self and Identity, 13(2), 128-145.

Sirois, F. M., Melia-Gordon, M. L., \& Pychyl, T. A. (2003). "I'll look after my health, later": An investigation of procrastination and health. Personality and Individual Differences, 35, 1167-1184.

Sirois, F., \& Pychyl, T. (2013). Procrastination and the priority of short-term mood regulation: Consequences for future self. Social and Personality Psychology Compass, 7(2), 115-127.

Stead, R., Shanahan, M. J., \& Neufeld, R. W. (2010). "I'll go to therapy, eventually": Procrastination, stress and mental health. Personality and Individual Differences, 49(3), 175-180.

Steel, P. (2007). The nature of procrastination: A meta-analytic and theoretical review of quintessential selfregulatory failure. Psychological bulletin, 133(1), 65-94.

Steel, P., Brothen, T., \& Wambach, C. (2001). Procrastination and personality, performance, and mood. Personality and Individual Differences, 30(1), 95-106.

Sutcliffe, K. R., Sedley, B., Hunt, M. J., \& Macaskill, A. C. (2019). Relationships among academic procrastination, psychological flexibility, and delay discounting. Behavior Analysis: Research and Practice, 19(4), 315-326.

Svartdal, F., \& Steel, P. (2017). Irrational delay revisited: Examining five procrastination scales in a global sample. Frontiers in Psychology, 8, 1927. 
Tice, D. M., \& Bratslavsky, E. (2000). Giving in to feel good: The place of emotion regulation in the context of general self-control. Psychological Inquiry, 11(3), 149-159.

Visser, L., Korthagen, F. A., \& Schoonenboom, J. (2018). Differences in learning characteristics between students with high, average, and low levels of academic procrastination: students' views on factors influencing their learning. Frontiers in Psychology, 9, 808.

Wang, S., Zhou, Y., Yu, S., Ran, L. W., Liu, X. P., \& Chen, Y. F. (2015). Acceptance and commitment therapy and cognitive-behavioral therapy as treatments for academic procrastination: A randomized controlled group session. Research on Social Work Practice, 27(1), 48-58.

Wolters, C. A. (2003). Understanding procrastination from a self-regulated learning perspective. Journal of educational psychology, 95(1), 179-187.

Wolters, C. A., Won, S., \& Hussain, M. (2017). Examining the relations of time management and procrastination within a model of self-regulated learning. Metacognition and Learning, 12(3), 381-399.

Zimmerman, B. J. (2000). Self-efficacy: An essential motive to learn. Contemporary educational psychology, 25(1), 82-91.

Publisher's Note Springer Nature remains neutral with regard to jurisdictional claims in published maps and institutional affiliations.

T. Hailikari Ph.D., is a Senior lecturer at the Centre for University Teaching and Learning. She teaches university pedagogy for university staff. Her research interests include learning and teaching at university. She holds a doctoral degree in University Pedagogy from the University of Helsinki.

N. Katajavuori Ph.D., is a Senior lecturer in university pedagogy at the Centre for University Teaching and Learning. Her research is related to students' well-being, relationship between well-being and learning process and the development of expertise in life sciences. She is also interested in how to promote students' well-being and how to enhance the development of expertise during university studies.

H. Asikainen Ph.D., is a Senior lecturer in university pedagogy at the Centre for University Teaching and Learning. Her research deals with questions concerning students' well-being and how to promote it during university studies. She is also interested in the relationship between well-being and learning processes. 